\title{
Abscisic Acid and Cytokinin-Induced Osmotic and Antioxidant Regulation in Two Drought-Tolerant and Drought-Sensitive Cultivars of Wheat During Grain Filling Under Water Deficit in Field Conditions
}

\author{
Mohammad-Reza SARAFRAZ-ARDAKANI ${ }^{1 *}$, Ramazan-Ali KHAVARI-NEJAD ${ }^{1,2}$, \\ Foad MORADI ${ }^{3}$, Farzaneh NAJAFI ${ }^{1}$ \\ ${ }^{1}$ Kharazmi University, Faculty of Biological Sciences, Tehran, Iran; sarafraz_ardakani@yahoo.com ("corresponding author); \\ Khavari-Nejad@yahoo.com; fnajafi@yahoo.com \\ ${ }^{2}$ Islamic Azad University, Department of Biology, Science and Research Branch, Tehran, Iran; \\ ${ }^{3}$ Agriculture and Biotechnology Research Institute, Karaj,Iran; foadmoradi@yahoo.com
}

\begin{abstract}
Phytohormones play critical roles in regulating plant responses to stress. The present study investigates the effect of cytokinin, abscisic acid and cytokinin/abscisic acid interaction on some osmoprotectants and antioxidant parameters induced by drought stress in two wheat cultivars (Triticum aestivum L.) of 'Pishgam' and 'MV-17' as tolerant and sensitive to drought during postanthesis phase, respectively grown in field conditions. The most considerable effect of the treatments was exhibited 21 days after anthesis. Under drought conditions, the flag leaf soluble carbohydrate content increased in both cultivars while starch content was remarkably decreased in 'Pishgam' as compared to 'MV-17'. Abscisic acid increased total soluble sugar and reduced starch more than other hormonal treatments, although it decreased studied monosaccharaides in 'Pishgam', especially. Drought stress induced high proportion of gylycinebetain and free proline in 'Pishgam' cultivar. Application of abscisic acid and cytokinin/abscisic acid interaction increased gylycinebetain and proline content in both cultivars under irrigation and drought conditions. The tolerant cultivar exhibited less accumulation of hydrogen peroxide and malondialdehyde in relation to significant increase of catalase and peroxidase activities and $\alpha$-tocpherol content under drought conditions. All hormonal treatments increased the named enzyme activities under both irrigation and drought conditions, while higher accumulation of $\alpha$-tocopherol was only showed in case of cytokinin application. Also, abscisic acid and cytokinin/abscisic acid could decrease drought-induced hydrogen peroxide and malondialdehyde level to some extent, although abscisic acid increased both of hydrogen peroxide and malondialdehyde content in irrigation phase, especially.
\end{abstract}

Keywords: Abscisic acid, antioxidant, osmoprotectant, cytokinin, drought stress, wheat cultivar

\section{Introduction}

On a global basis, drought stress (including soil and/or atmospheric water deficit), in conjunction with coincident high temperature and radiation is one limiting factor for plant survival and productivity in different conditions such as agriculture (Chaves et al., 2003). Wheat (Triticum aestivum L.), as one of the crucially important food, is especially threaten by water deficit during flowering and grain filling period (Lantican et al., 2005). Drought stress induces various biochemical and physiological responses in plants because of Alteration of water content within the plant tissue and oxidative stress such as protein denaturation, lipid peroxidation, MDA accumulation and pigment degradation due to produced reactive oxygen species (ROS - Chaves et al., 2003; Gill and Tuteja, 2010). Therefore, accumulation of sugars (such as raffinose family oligosaccharides (RFO), sucrose, trehalose and sorbitol), sugar alcohols (such as manitol), amino acids (such as proline (Pro), and amines (such as glycine betaine and polyamines) is for osmoprotection in plant for water preservation (Seki et al., 2007; Yordanov et al., 2000). Also up-regulating of enzymatic and non-enzymatic antioxidants is in order to overcome oxidative stress. The most important antioxidant enzymes are superoxide dismutase (SOD), catalase (CAT) and peroxidase (POX). SOD converts ROS into $\mathrm{H}_{2} \mathrm{O}_{2}$ and $\mathrm{O}_{2}$, while CAT and POX convert $\mathrm{H}_{2} \mathrm{O}_{2}$ into $\mathrm{H}_{2} \mathrm{O}$ (Chaves et al., 2003; Gill and Tuteja, 2010). 
Besides, non-enzymatic antioxidant such as vitamin E, carotenoids (carotene and xanthophylls) and soluble antioxidant including ascorbate and glutathione can also quench ROS and stabilize photosynthetic complexes (Chaves et al., 2003; Gill and Tuteja, 2010; Liu et al., 2011).

Phytohormones create an ability in plants to adapt to abiotic stresses by mediating a wide range of adaptive responses. $\mathrm{CK}$ and $\mathrm{ABA}$ cause different manners to encounter the drought stress. In water stressed plants, CK synthesis in the roots and delivery to the leaves is usually less but its degradation might be increased. In consequence, decreased CK content in leaves has been observed (Pospisilova et al., 2000; Pospisilova, 2003). In spite of the latter studies, CKs may partially ameliorate negative effects of water stress by stimulating osmotic adjustment (Merevites et al., 2011) and directly or indirectly scavenging ROS (Stoparic and Maksimovic et al., 2008). The involvement of $\mathrm{ABA}$ in mediating drought stress has been extensively researched. ABA plays a critical role in regulating plant water status through guard cells and growth as well as by induction of genes that encode enzymes and other proteins involved in cellular dehydration tolerance (Pospisilova et al., 2000; Pospisilova, 2003; Ghassemian et al., 2008).

The present study determines the comparative effect of $\mathrm{CK}, \mathrm{ABA}$ and $\mathrm{CK} / \mathrm{ABA}$ interaction on the osmotic adjustment and some components of antioxidant system in two wheat (Triticum aestivum L.) cultivars differing in the degree of drought resistance ('Pishgam' as drought-tolerant cultivar and 'MV-17' as drought-sensitive cultivar) during post-anthesis phase.

\section{Materials and methods}

\section{Plant materials and growth conditions}

A homogenous lot of wheat seeds (Triticum aestivum $\mathrm{L}$.) of two cultivars, 'Pishgam' (drought- tolerant) and 'MV-17' (drought-sensitive) were obtained from the Seed and Plant Improvement Institute of Iran. The experimental period started on November 22, 2009 and ended on April 25, 2010. Climate temperature and rainfall from sowing to harvest during experimental period are presented in Table 1. A composite soil sample (from 48 points) was collected from 0 30 and 30-60 cm depth during experimental period and was analyzed in the laboratory. Details of soil physical and chemical properties of the experimental site are given in Table 2. Factorial experiment was based on the randomized complete blocks with three replicates under irrigation (hormonal and non-hormonal treatments) and drought (hormonal and non-hormonal treatments) conditions. The seeds were sown on field, in 48 rows $20 \mathrm{~cm}$ apart with the density of 400 seeds $\mathrm{m}^{-2}$. The needed nitrogen for wheat growth based on the field experiment results was $60 \mathrm{~kg}$ net nitrogen per hectare from urea source added to the soil in fall (Feyziasl and Valizadeh, 2001 and 2003). The needed phosphorous was supplied on the basis of soil test and phosphorous deficit from critical level in soil $(9 \mathrm{mg}$ per hectare-Feyziasl et al., 2004). The experimental field was covered by a shelter. Watering of irrigation treatments were routinely done until the end of growth period while watering of drought stress treatment was interrupted at the start of second week of flowering stage. Also, degree of soil moisture was weekly measured on by time domain reflectometry (TDR-table 3). Application of CK (BA $150 \mu \mathrm{L})$ and ABA $(100 \mu \mathrm{L})$ treatments was begun as foliar spray in irrigation and drought conditions in the start of second and fourth week after anthesis, respectively. Therefore hormonal treatments were complete at 21 and 28 days after anthesis and the most significant data was obtained at $21 \mathrm{DAA}$. Then in the treatments (irrigation and drought stress) after the removal of marginal effects, 60 plants were randomly selected and cut in $0,7,14,21$ and 28 days after the pollination stage, respectively. Flag leaves of the samples were separated and wrapped in aluminum foil and were immediately put in liquid nitrogen. The samples were then dried in freeze dryer ($120^{\circ} \mathrm{C}$ ) and were kept at $-80^{\circ} \mathrm{C}$ until next measurement, although many of samples were only transferred at $-80^{\circ} \mathrm{C}$ immediately in related to enzyme activity assay.

Tab. 1. Mean monthly temperature and rainfall during crop growth

\begin{tabular}{|c|c|c|c|c|c|c|}
\hline $\begin{array}{c}\text { Month } \rightarrow \\
\text { Conditions } \\
\downarrow\end{array}$ & $\begin{array}{l}\ddot{0} \\
\text { हूँ } \\
\text { Zे }\end{array}$ & 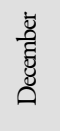 & 密 & $\begin{array}{l}\text { 胥 } \\
\text { 这 }\end{array}$ & $\frac{\overrightarrow{5}}{\mathrm{~g}}$ & 娄 \\
\hline Temperature $\left({ }^{\circ} \mathrm{C}\right)$ & 10.3 & 1.9 & 11.9 & 13.3 & 20.9 & 23.7 \\
\hline Rainfall (mm) & 8.4 & 11.6 & 17.8 & 16.9 & 8.7 & 5.8 \\
\hline
\end{tabular}

Tab. 2. Soil physical and chemical properties of the experimental site $(0-$ 30 and 30-60 cm depth)

\begin{tabular}{|c|c|c|c|c|c|c|c|c|c|}
\hline 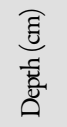 & $\stackrel{I}{2}$ & 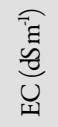 & $\frac{\grave{\jmath}}{\circlearrowright}$ & है है & $\frac{\overparen{E}}{\stackrel{\Xi}{\vec{Z}}}$ & 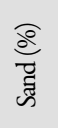 & $\frac{\overparen{\varrho}}{\stackrel{4}{\hookleftarrow}}$ & $\frac{\widehat{d}}{\stackrel{\frac{d}{d}}{d}}$ & 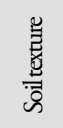 \\
\hline $0-30$ & 7.44 & 1.23 & 1.19 & 17.06 & 463 & 19.6 & 41.1 & 29.4 & $\begin{array}{l}\text { Clay } \\
\text { loam }\end{array}$ \\
\hline $30-60$ & 7.51 & 1.38 & 1.04 & 39.01 & 791 & 23.9 & 45.6 & 21.2 & Loam \\
\hline
\end{tabular}

\section{Estimation of carbohydrate content}

$0.03 \mathrm{~g}$ freeze dried samples of flag leaf were ground and extracted three times $50 \mathrm{~mL}$ hot $80 \%$ ethanol (Gill et al., 2003). Soluble sugars were determined based on the method of phenol-sulphuric acid by Dubois et al., 1956. The reducing sugars were quantitatively estimated in the obtained extract, by Nelson's method (Nelson, 1944). Starch content was also determined using the method of phenol-sulfuric acid by Dubois et al., 1956. Levels of glucose, sucrose and fructose were determined using twodimensional HPLC (controller, Waters 600 s; pump, Waters 626; autosampler, Waters 717; Waters, Massachusetts, USA) using U.V. detector and C-18 column according to Albertson and Grof, 2007). Sugars were quantified from standard curves calculated from external standards preceding and following each group of samples with the concentration of $0,5,10,15,20,25$ and $30 \mathrm{mM}$ of glucose.

\section{Free proline and gylycinebetaine determination}

Free proline content was quantified according to the method of Bates et al. (1973). Free gylycinebetaine was determined according to Grieve and Maas (1984).

\section{Oxidative stress parameters}

Lipid peroxidation was measured in terms of content of malondialdehyde (MDA, $\varepsilon=155 \mathrm{mmol}^{-1} \mathrm{~cm}^{-1}$ ), a product 
356

of lipid peroxidation, following the method of Heath and Packer (1968). $\mathrm{H}_{2} \mathrm{O}_{2}$ content was determined according to Velikova et al. (1990). The content of $\mathrm{H}_{2} \mathrm{O}_{2}$ was calculated by comparison with a standard calibration curve previously made by using different concentration of $\mathrm{H}_{2} \mathrm{O}_{2}$.

Estimation of vitamin $\mathrm{E}$ ( $\alpha$-tocopherol)

A level of $\alpha$-tocopherol was determined using twodimensional HPLC system (detector: florescence, mobile phase: flow intensity: $1.3 \mathrm{ml} \mathrm{min}{ }^{-1}$, excited wavelength: 288 $\mathrm{ml} \mathrm{min}{ }^{-1}$, excited wavelength: $288 \mathrm{~nm}$, emission wavelength: $322 \mathrm{~nm}$ ) with $\mathrm{C}_{18}$ column by method of Botsoglou et al. (1998).

\section{Measurement of antioxidant enzyme activity}

After homogenized with liquid nitrogen, $0.3 \mathrm{~g}$ of flag leaves were suspended in $3 \mathrm{ml}$ of ice-cold HEPES buffer $(25$ $\mathrm{mM}, \mathrm{pH} 7.8$ ) which contained $0.2 \mathrm{mM}$ EDTA and $2 \%$ PVP. The homogenate was centrifuged at $48 \mathrm{C}$ and 12,000 $\times \mathrm{g}$ for $20 \mathrm{~min}$, and the resulting supernatant was used for determination of CAT and POD (Ramiro et al., 2006).

A modification of the method of Aebi (1984) was used to assay catalase activity. Activity of peroxidase was measured according to the method of Chance and Maehly (1955). One unit of catalase activity corresponded to the amount of enzyme that decomposes $1 \mu$ mole of
$\mathrm{H}_{2} \mathrm{O}_{2} / \mathrm{min} / \mathrm{g}$ fresh wt. One unit of peroxidase is the amount of enzyme required to oxidize one $\mu$ mole of guaiacol by $\mathrm{H}_{2} \mathrm{O}_{2}$ at test conditions.

\section{Statistical analysis}

The mean values of studied parameters were taken from the measurements of three replicates and the "Standard Error" of the means was calculated. One-way ANOVA was applied to determine the significance of the results between different treatments and then Duncan multiple range tests $(p<0.05)$ were performed. All the statistical analyses were done using the Statistical Package for Social Sciences (SPSS) for Windows (version 18.0). All significant different were calculated as percentage with two digits after decimal.

\section{Results and discussion}

\section{Carbohydrate content}

Earlier reports mentioned that sugars protect the cells during drought by two mechanisms. First, the hydroxyl groups of sugars may substitute for water to maintain hydrophilic interactions in membranes and proteins during dehydration. Thus, sugars interact with proteins and membranes through hydrogen-bonding, thereby preventing protein denaturation. Secondly, sugars are a major

Tab. 3. Measurement of soil moisture as sampling in 0-30 $\mathrm{cm}$ and 30-60 cm depths

\begin{tabular}{|c|c|c|c|c|c|c|c|c|c|c|c|c|}
\hline \multirow{3}{*}{ 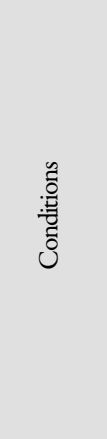 } & \multirow{3}{*}{ 莺 } & \multirow{3}{*}{$\frac{\text { 营 }}{\frac{0}{\overrightarrow{0}}}$} & \multicolumn{2}{|c|}{$\begin{array}{l}\text { 总 } \\
\text { 竞 } \\
\text { 员 }\end{array}$} & \multicolumn{2}{|c|}{ 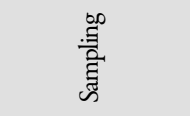 } & \multicolumn{2}{|c|}{$\begin{array}{l}\text { 壱 } \\
\text { 壳 } \\
\text { 今 }\end{array}$} & \multicolumn{2}{|c|}{ 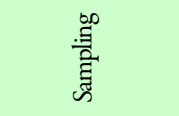 } & \multicolumn{2}{|c|}{ 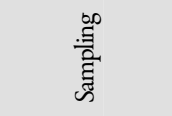 } \\
\hline & & & 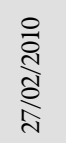 & $\begin{array}{l}\stackrel{0}{\circ} \\
\text { ते } \\
\text { ปิ }\end{array}$ & $\begin{array}{l}\stackrel{\circ}{\stackrel{d}{d}} \\
\stackrel{m}{f}\end{array}$ & 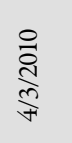 & $\begin{array}{l}\stackrel{0}{\vec{D}} \\
\stackrel{\text { In }}{=}\end{array}$ & $\begin{array}{l}\stackrel{0}{0} \\
\stackrel{N}{ٍ} \\
\Xi\end{array}$ & $\begin{array}{l}\stackrel{0}{\circ} \\
\stackrel{N}{8} \\
\stackrel{\infty}{\infty}\end{array}$ & $\begin{array}{l}\stackrel{0}{\circ} \\
\stackrel{2}{\delta} \\
\stackrel{\infty}{\infty}\end{array}$ & 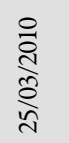 & 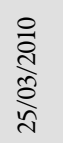 \\
\hline & & & ह̂ & $\stackrel{\circ}{\stackrel{0}{0}}$ & Еૈ & $\stackrel{\circ}{\circ}$ & 䒽 & $\stackrel{\circ}{\stackrel{0}{0}}$ & 苂 & $\stackrel{\circ}{\stackrel{0}{0}}$ & 尽 & $\stackrel{\circ}{\stackrel{0}{0}}$ \\
\hline Drought & Pishgam & $0-30$ & 36.0 & 28.2 & 49.2 & 15.7 & 54.9 & 11.6 & 48.4 & 15.4 & 46.4 & 14.3 \\
\hline Drought & Pishgam & $30-60$ & 37.5 & 23.9 & 38.9 & 20.9 & 36.8 & 16.1 & 38.2 & 19.7 & 31.1 & 19.8 \\
\hline Drought & MV17 & $0-30$ & 35.3 & 21.6 & 50.7 & 14.1 & 59.9 & 9.8 & 50.7 & 12.2 & 50.7 & 12.1 \\
\hline Drought & MV17 & $30-60$ & 41.4 & 21.1 & 42.5 & 18.1 & 42.2 & 14.3 & 39.8 & 17.4 & 35.7 & 17.6 \\
\hline Irrigation & Pishgam & $0-30$ & 32.5 & 28.8 & 37.5 & 29.8 & 45.5 & 17.1 & 37.9 & 29.7 & 38.5 & 21 \\
\hline Irrigation & Pishgam & $30-60$ & 33.9 & 25.3 & 34 & 25.3 & 34.5 & 18.4 & 37.2 & 22.7 & 29.2 & 22.6 \\
\hline Irrigation & MV17 & $0-30$ & 34.9 & 19.6 & 41 & 27.4 & 43.0 & 17.1 & 34.2 & 30.3 & 36.4 & 21 \\
\hline Irrigation & MV17 & $30-60$ & 37.9 & 24.1 & 36.7 & 22.3 & 39.3 & 17.1 & 36.7 & 20.6 & 33.2 & 21 \\
\hline
\end{tabular}

contributing factor to vitrification, which is the formation of a biological glass in the cytoplasm of dehydrated cells. Sugars helped to maintain osmotic adjustment during drought conditions. Also, it has been claimed that even sugar flux may be a signal for metabolic regulation (Xue $e t$ al., 2008).

Results revealed that, total soluble sugars (TSS) increased during 21 days after anthesis (DAA) by 115.91 and $29.81 \%$ in 'Pishgam' and 'MV-17' under drought conditions as compared to normally-watered plants, respectively. According to our experiments, significant increase in the amount of reducing sugars $92.91 \%$ was recorded in tolerant cultivar during the drought conditions, as compared to the irrigation conditions at the time period of 21 DAA. While, the sensitive cultivar showed $28.03 \%$ increase in reducing sugars at 21 DAA. This study revealed that, drought stress could reduce starch content of two cultivars especially by 31.06 and $9.78 \%$ in 'Pishgam' and 'MV-17' at 21 DAA, respectively. In related to results above, TSS/starch ratio increased under drought conditions in either cultivar that reached the maximum at 21 DAA by $211.0 \%$ in 'Pishgam' and by $44.44 \%$ in 'MV-17' (Fig. 1).

During drought conditions, fructose content had tremendous increase $(107.75 \%)$ at 21 DAA. The same 
situation was observed in the susceptible cultivar with lesser extent with an increase of $45.79 \%$. Under drought conditions, glucose level increased only in 'Pishgam' by $53.84 \%$ at 21 DAA, significantly. Also, sucrose level increased in 'Pishgam' by $255.18 \%$ at 21 DAA. 'MV-17' cultivar also showed $22.64 \%$ increase in sucrose level at 21 DAA (Fig 2).

The accumulation of sugars in response to drought stress and decrease of starch content due to the decline of photosynthesis and its degradation was studied in wheat leaves during drought (Xue et al., 2008). Increased level of sucrose, glucose and fructose during drought conditions
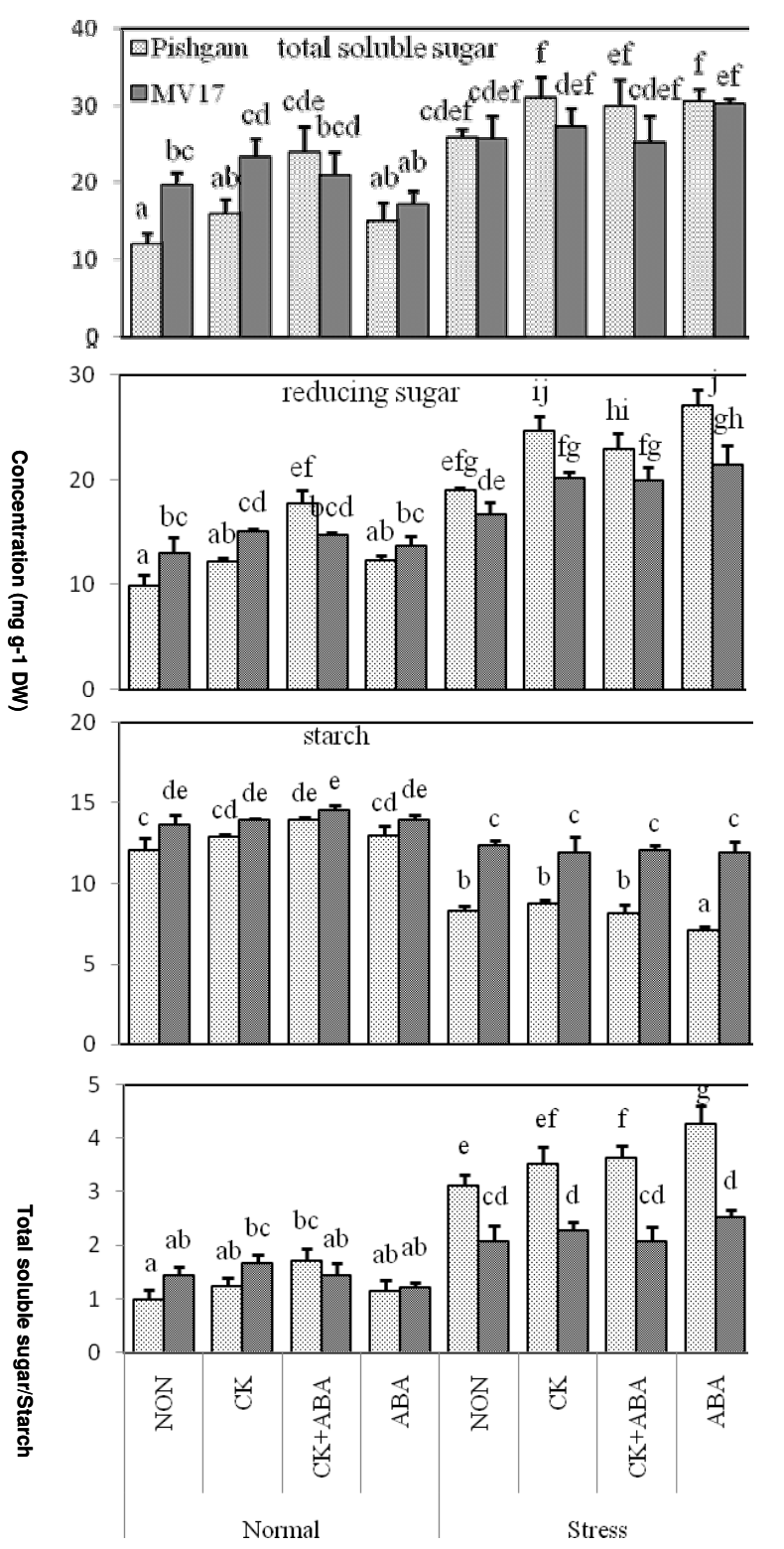

Fig. 1. Effect of hormonal treatments of $\mathrm{CK}, \mathrm{ABA}$ and $\mathrm{CK} / \mathrm{ABA}$ on total soluble sugar, reducing sugar, starch content and total soluble sugar/starch ratio under irrigation and drought condition in flag leaves during grain filling in two wheat cultivars (drought tolerant cv. 'Pishgam' (white columns) and drought sensitive cv. 'MV-17' (black columns). Data are shown as mean \pm SD of three independent implies that complex carbohydrates, such as starch, hydrolyze to simple sugars such as hexoses during drought conditions. Studies with a variety of plants demonstrate that drought induces these carbohydrates into sugar alcohols and proline (Wang et al., 1996). Our results are supported by study that reported genes encoding cytoplasmic and vacuolar enzymes in the pathways leading to glucose, fructose and fructan production were up-regulated in the wheat leaves during drought stress although enzymes involved in carbon fixation (Calvin cycle) were Conversely reduced (Xue et al., 2008).

Plant hormones such as; CK and ABA play important roles in conferring tolerance to environmental stress as effect on carbohydrate content (Pospisilova, 2003).

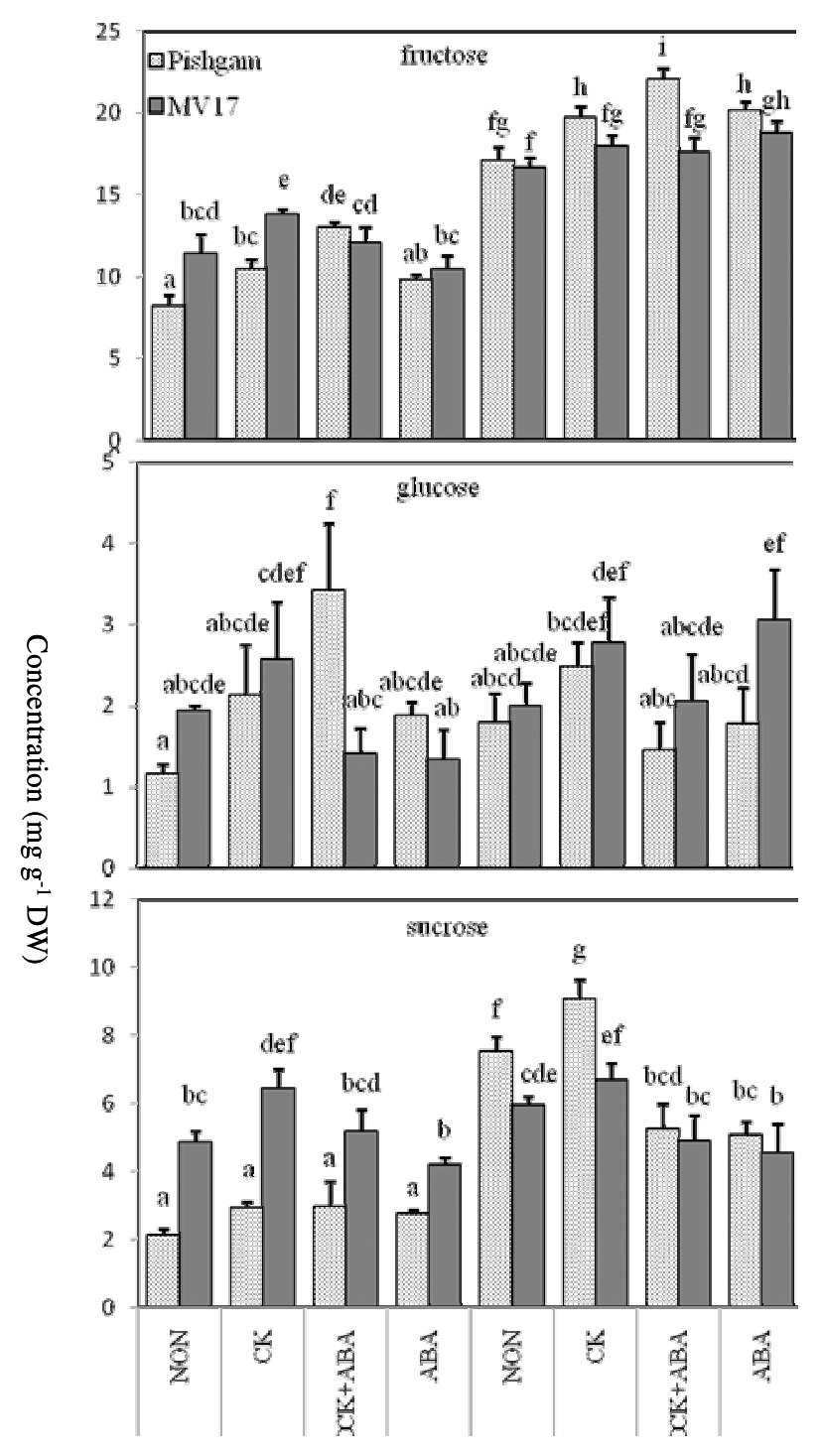

Fig. 2. Effect of hormonal treatments of $\mathrm{CK}, \mathrm{ABA}$ and $\mathrm{CK} / \mathrm{ABA}$ on fructose, glucose and sucrose content under irrigation and drought condition in flag leaves during grain filling in two wheat cultivars (drought tolerant cv. 'Pishgam' (white columns) and drought sensitive cv. 'MV-17' (black columns). Data are shown as mean \pm SD of three independent measurements 
In well-watered plants of 'Pishgam', CK/ABA treatment increased TSS at 21 DAA by $100.25 \%$. Hormonal treatments had no significant effect on TSS of sensitive cultivar during irrigation conditions. None of hormonal treatments had significant effect on TSS content in 'Pishgam' and 'MV-17' under drought conditions. At the 21 DAA, during irrigation conditions, the hormonal treatment of $\mathrm{CK} / \mathrm{ABA}$ increased the reducing sugars by $79.75 \%$ as compared to the non-hormone treatment in 'Pishgam'. While, significant effect of hormonal treatments was not seen on its of 'MV-17' in latter conditions. The results have shown that $\mathrm{ABA}$ increased reducing sugar content during drought conditions more effectively than other hormonal treatments by 42.07 and $27.98 \%$ in 'Pishgam' and 'MV-17' at 21 DAA, respectively. Under irrigation conditions, only $\mathrm{CK} / \mathrm{ABA}$ increased the starch content by 15.99 and $6.05 \%$ at $21 \mathrm{DAA}$ in tolerant and sensitive cultivar, respectively. Interestingly, under drought conditions, only ABA decreased starch content by $14.28 \%$ in 'Pishgam'. Although, ABA decreased starch level of 'MV$17^{\prime}$ but it was not a significant reduction. This shows the

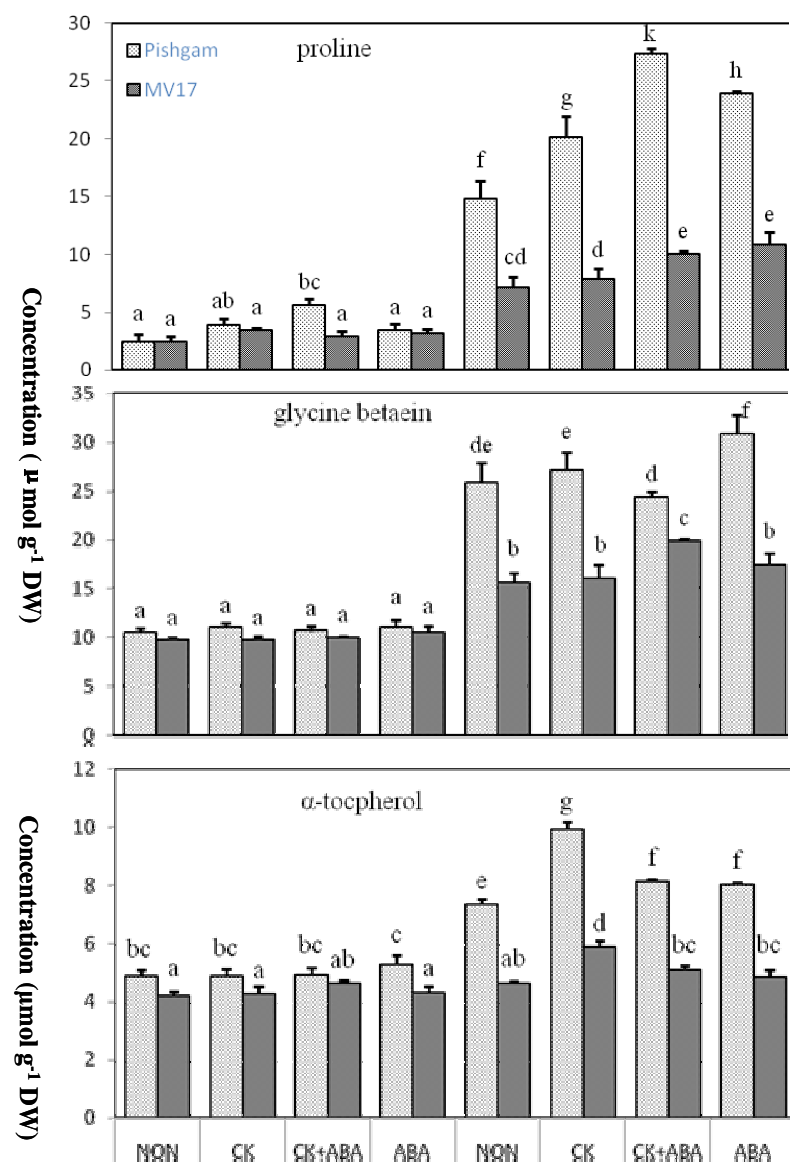

Fig. 3. Effect of hormonal treatments of $\mathrm{CK}, \mathrm{ABA}$ and $\mathrm{CK} / \mathrm{ABA}$ on glycinebetaine and proline content under irrigation and drought condition in flag leaves during grain filling in two wheat cultivars (drought tolerant cv. 'Pishgam' (white columns) and drought sensitive cv. 'MV-17' (black columns). Data are shown as mean $\pm \mathrm{SD}$ of three independent measurements significantly effective behaviour of $\mathrm{ABA}$ on starch content in the stems of wheat cultivar. In well watered plants, only $\mathrm{CK} / \mathrm{ABA}$ increased significantly TSS/starch ratio at 21 DAA by $71.0 \%$ in 'Pishgam'. In drought conditions, effect of ABA was much pronounced which was able to elevate TSS/starch ratio by $37.62 \%$ at 21 DAA in tolerant cultivar as compared with non-hormone treatment effect of other hormonal treatments was not significant in both cultivars (Fig. 1).

$\mathrm{CK} / \mathrm{ABA}$ caused the most significant increase in fructose content of 'Pishgam' at 21 DAA by 57.69 and $28.64 \%$ under irrigation and drought conditions, respectively. Fructose content of sensitive cultivar increased remarkably by $21.36 \%$ under irrigation conditions at 21 DAA when it applied CK in compared to other hormonal treatments. But under drought conditions, ABA caused the most increase in fructose content by $13.03 \%$. Under wellirrigated conditions, $\mathrm{CK} / \mathrm{ABA}$ caused the most significant increase by $193.16 \%$ in glucose content of 'Pishgam' at 21 DAA, while hormonal treatments did not create its of 'MV17'. Under drought conditions, hormonal treatments of $\mathrm{CK}$ and $\mathrm{ABA}$ increased significantly glucose level by 37.77 and $52.5 \%$ in 'Pishgam' and 'MV-17' at 21 DAA, respectively. Application of $\mathrm{ABA}$ caused a decrease in sucrose level of 'Pishgam' and 'MV-17' cultivars by 42.82 and $63.36 \%$ at $21 \mathrm{DAA}$, respectively under irrigation conditions. The interaction of $\mathrm{CK}$ and $\mathrm{ABA}$ also decreased sucrose level in 'Pishgam' and 'MV-17' although its effect was less than individual $\mathrm{ABA}$ treatment. Under drought conditions, $\mathrm{ABA}$ caused the most significant effect on sucrose level by decreasing it 32.66 and $23.82 \%$ in 'Pishgam' and 'MV-17' at 21 DAA, respectively (Fig. 2).

CKs are important in the development of plants' photosynthetic apparatus by directly effecting on chloroplast, increasing the photochemical activity of photosystem II (PS II) and reducing chlorophyll degradation (Goltsev et al. 2001). Therefore, it can be presumed that the foliar application of CK had the ability to increase carbohydrate content due to a good effect on photosynthesis system in our work. In agreement with our study, foliar application of kinetin increased total carbohydrate in leaves of Codiaeum variegatum in normal condition (Mazher et al., 2011) and also in water-logged or seawater-treated Vigna sinensis and Zea mays plants (ElShahaby et al., 2003). ABA-induced decrease in starch content and increase in reducing sugars in 'Pishgam' especially which may partly be responsible for improving relative water content of plant leaves because make osmotic potential more negative (Pospisilova, 2003). This can be explained by the studies of Lee et al. (2008), suggesting that exogenous application of $\mathrm{ABA}$ increased the activity of certain enzymes like-amylase and ribonuclease in white clover leaves. These enzymes might breakdown starches and other materials to make osmotic potential more negative. Moreover, ABA excited many of metabolism pathways including biosynthesis of osmolytes that need carbon framework of sugars. Therefore, ABA can be effective on utilization of TSS in different metabolism pathways (Verslues and Bray, 2006) and a probable reason that we did not show significant change or increase of TSS, glucose and sucrose in hormonal treatment of ABA under drought, although fructose level increased. 


\section{Proline and glycine betaine content}

Accumulation of proline (Pro) and glycine betaine (GB) may be a response characteristic of cultivars under water deficit which it works as osmotic adjustor. Moreover, GB is essential in stabilizing the macromolecules, such as РSП complex and rubisco, and to protect membranes from lipid peroxidation. Pro is also considered as a potent antioxidant and inhibitor of protein denaturation, and preservation of enzyme structure (Chaves et al., 2003). The present results have shown that Pro content increased 488 and 187\% in 'Pishgam' and 'MV-17', respectively under drought conditions at 21 DAA. Under drought conditions, GB content also showed an increase of 138.37 and $60.82 \%$ in 'Pishgam' and 'MV-17' cultivars, respectively, at 21 DAA (Fig. 3). In agreement with our study, the rate of Pro accumulation was significantly higher in drought-tolerant cultivars than drought-sensitive cultivars of wheat and olive. Also, in species such as wheat (Triticum aestivum) and sorghum (Sorghum bicolor), tolerant genotypes normally accumulate more GB than sensitive genotypes in response to stress. This relationship, however, is not universal in salt and drought tolerance (Ashraf and Foolad, 2007).

As well as carbohydrates, phythormones can alternate levels of other osmoprotectants as Pro in plants under water stress (Pospisilova, 2003). Hormonal treatments had more effect on tolerant cultivar than the susceptible one under well-irrigated and drought conditions. CK/ABA caused 123.71 and $82.74 \%$ increase in Pro level of 'Pishgam' under irrigation and drought conditions, respectively. But in sensitive cultivar, under well-irrigated conditions, CK caused 38.95\% increase in Pro at 21 DAA. Under drought conditions, $\mathrm{ABA}$ also increased Pro content of 'MV-17' by $51.88 \%$ at 21 DAA. Under irrigation conditions, hormonal treatments did not show significant effect on GB content in either two cultivars during DAA. Under drought conditions, $\mathrm{CK} / \mathrm{ABA}$ caused the most effect on GB content so that increased it by $26.78 \%$ in 'MV-17', while ABA treatment increased GB by $19.23 \%$ in 'Pishgam' more than other hormonal treatments (Fig. 3).

The light-dependence of stress-induced Pro accumulation, which is also CK-inducible, has been demonstrated in several higher plants (Hare et al., 1997). Elevated CK levels promoted survival under water-stress conditions, inhibited leaf senescence and induced increased Pro levels (Nishiyama et al., 2011). In light of the previous information, proline accumulation in plants is mediated by both $\mathrm{ABA}$-dependent and $\mathrm{ABA}$-independent signaling pathways. ABA is known to regulate expression of P5CS gene which is involved in proline biosynthesis (Ashraf and Foolad, 2007). In some plants as Arabidopsis causal link between $\mathrm{ABA}$ and proline accumulation was suggested and it was shown that exogenous application of $\mathrm{ABA}$ increases the level of AtPSCS1 and AtP5CS2 transcripts (Strizhov, 1997). Although this phenomenon is common, the role of $\mathrm{ABA}$ in regulating Pro accumulation has still been a matter of confusion and debate, since contradictory data was obtained in different species by different researchers (Verslues and Bray, 2006).

Malondialdehyde and hydrogen peroxide content

lipid peroxidation and $\mathrm{H}_{2} \mathrm{O}_{2}$ accumulation not only directly affecting normal cellular functioning, but also aggravating the oxidative stress through production of lipid- derived radicals in abiotic stresses such as drought. Although, $\mathrm{H}_{2} \mathrm{O}_{2}$ at low concentrations acts as a signal molecule involved in acclimatory signaling triggering tolerance to various biotic and abiotic stresses (Gill and Tuteja, 2010).

$\mathrm{H}_{2} \mathrm{O}_{2}$ content increased significantly under drought condition in 'Pishgam' and 'MV-17' by 254.61 and $437.40 \%$, respectively during 21 DAA. According to increased $\mathrm{H}_{2} \mathrm{O}_{2}$ level under drought conditions, Malondialdehyde (MDA) content increased by 503.43 and $750 \%$ in tolerant and sensitive cultivars, respectively (Fig. 4). Many works proved increasing of $\mathrm{H}_{2} \mathrm{O}_{2}$ and MDA under drought stress in cultivars, while susceptible cultivars elevated $\mathrm{H}_{2} \mathrm{O}_{2}$ and MDA more than tolerant cultivars (Chaves et al., 2003).

Under irrigation condition, significant increase of $\mathrm{H}_{2} \mathrm{O}_{2}$ content was only observed by ABA application at $21 \mathrm{DAA}$ in 'Pishgam' and 'MV-17' by 27.69 and $23.66 \%$, respectively. Generally, all hormonal treatments decreased $\mathrm{H}_{2} \mathrm{O}_{2}$ content under drought condition. However, during 21 DAA, the most reduction of $\mathrm{H}_{2} \mathrm{O}_{2}$ content of 'Pishgam' and 'MV-17' was induced by $\mathrm{CK} / \mathrm{ABA}$ interaction by 140.10 and 33.33\%, respectively. Under irrigation conditions, ABA application caused considerably a significant increase of 62.25 and $73.23 \%$ in MDA content of 'Pishgam' and 'MV-17' cultivars at $21 \mathrm{DAA}$, respectively. However, under drought conditions, CK/ABA increased MDA content by 66.28 and $31.96 \%$ in 'Pishgam' and 'MV$17^{\prime}$ at 21 DAA, respectively (Fig. 4).

Increasing $\mathrm{H}_{2} \mathrm{O}_{2}$ level during irrigation is due to particular role of $\mathrm{ABA}$ on plasma-membrane $\mathrm{NADPH}$ oxidase complex and its-produced $\mathrm{H}_{2} \mathrm{O}_{2}$ (Ghassemian et al., 2008). Therefore, increased level of $\mathrm{H}_{2} \mathrm{O}_{2}$ caused oxidative damages as MDA production that was more partially in

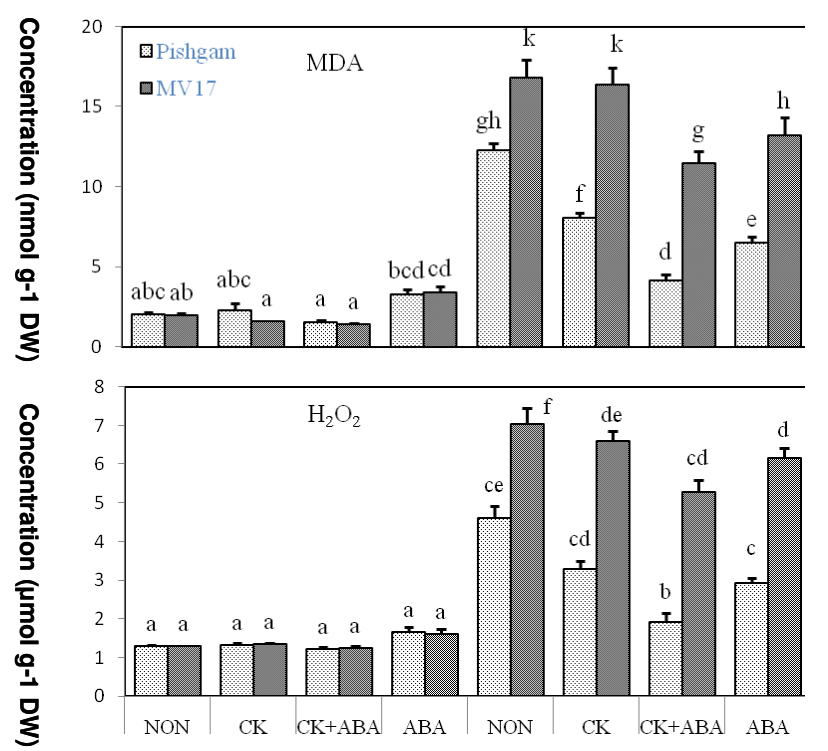

Fig. 4. Effect of hormonal treatments of $\mathrm{CK}, \mathrm{ABA}$ and CK/ABA on $\mathrm{H}_{2} \mathrm{O}_{2}$ and MDA content under irrigation and drought condition in flag leaves during grain filling in two wheat cultivars (drought tolerant cv. 'Pishgam' (white columns) and drought sensitive cv. 'MV-17' (black columns). Data are shown as mean \pm SD of three independent measurements 
360

'MV-17', although a level of $\mathrm{H}_{2} \mathrm{O}_{2}$ is necessary for signaling and up-regulation of antioxidants (Ghassemian et al., 2008). $\mathrm{ABA}$ effect on up-regulation antioxidant system (Ghassemian et al., 2008) and direct and indirect effect of CK on inhibition of ROS (Stoparic and Maksimovic, 2008) caused that $\mathrm{CK} / \mathrm{ABA}$ interaction inhibited $\mathrm{H}_{2} \mathrm{O}_{2}$ and MDA accumulation in drought condition higher than effect of individual $\mathrm{ABA}$ or $\mathrm{CK}$ treatment on $\mathrm{H}_{2} \mathrm{O}_{2}$ and MDA content.

\section{$\alpha$-tocopherol}

Drought stress excited the molecule and enzyme antioxidant in different cell compartments. Antioxidant capacity is greatly dependent on the severity of the stress as well as the species and the development stage (Chaves et al., 2003). $\alpha$-tocopherol as a constitutive component of lilpid matrix of thylakoid membrane has a photoprotective and stabling function. In agreement with previous study, higher $\alpha$-tocopherol contents occurred in drought-tolerance species than in susceptible one (Chaves et al., 2003). Also, Overexpression of VTE1 (Tocopherol cyclase) from Arabidopsis in transgenic tobacco plants, showed decrease in LPO, electrolyte leakage and $\mathrm{H}_{2} \mathrm{O}_{2}$ content in drought stress (Liu et al., 2008).

$\alpha$-tocopherol content showed a 50.20 and $10.76 \%$ increase in 'Pishgam' and 'MV-17' at 21 DAA under drought condition, respectively. Under irrigation conditions, only $\mathrm{CK} / \mathrm{ABA}$ caused a $10.55 \%$ significant increase in $\alpha$-tocopherol content of 'MV-17' at $21 \mathrm{DAA}$. Under drought conditions, CK treatment caused the most significant increase in $\alpha$-tocopherol content of 'Pishgam' and 'MV-17' by 27.69 and $26.99 \%$ at 21 DAA, respectively (Fig. 3).

It was suggested that, the increased $\alpha$-tocopherol level in flag leaf tissue under CK treatment might be in related to especial CK effect on the chloroplast development and stability that is an important synthesis and accumulation location for vitamin E (Hare et al., 1997). Nevertheless, the role of $A B A$ proved in increase of $\alpha$-tocopherol and Lascorbic acid in transcriptional and post-transcriptional levels (Ghassemian et al., 2008), ABA application had nonsignificant effect on its of tolerant and sensitive cultivars in this study.

\section{Antioxidant enzymes}

Undoubtedly, catalase (CAT) and peroxidase (POD) are the most important antioxidant enzymes that scavenge $\mathrm{H}_{2} \mathrm{O}_{2}$ as well as APX (Liu et al., 2011). During the present study, 151.89 and $64.7 \%$ increase in CAT activity was seen for 'Pishgam' and 'MV-17' at 21 DAA under drought stress, respectively. Also, the results have shown that 214.58 and 90.90\% increase in POD activity for 'Pishgam' and 'MV-17' under drought stress at $21 \mathrm{DAA}$, respectively. More increased activity of POD and CAT in tolerant cultivar was related to less increased MDA content under drought condition (Fig. 5). These results are in line with those related to tolerant and sensitive cultivars of maize seedling under water deficit (Chugh et al., 2011). As previous reviews (Chaves et al., 2003), a drought-tolerance cultivar can employ great activities of antioxidant enzymes than a drought-sensitive cultivar under drought. The increased activities of anti-oxidative enzymes, induced by moderate drought stress can protect cell membranes, proteins and metabolic machinery, which would preserve sub-cellular structure from damage as a result of cell dehydration (Gill and Tuteja, 2010). Consequently, a drought tolerance

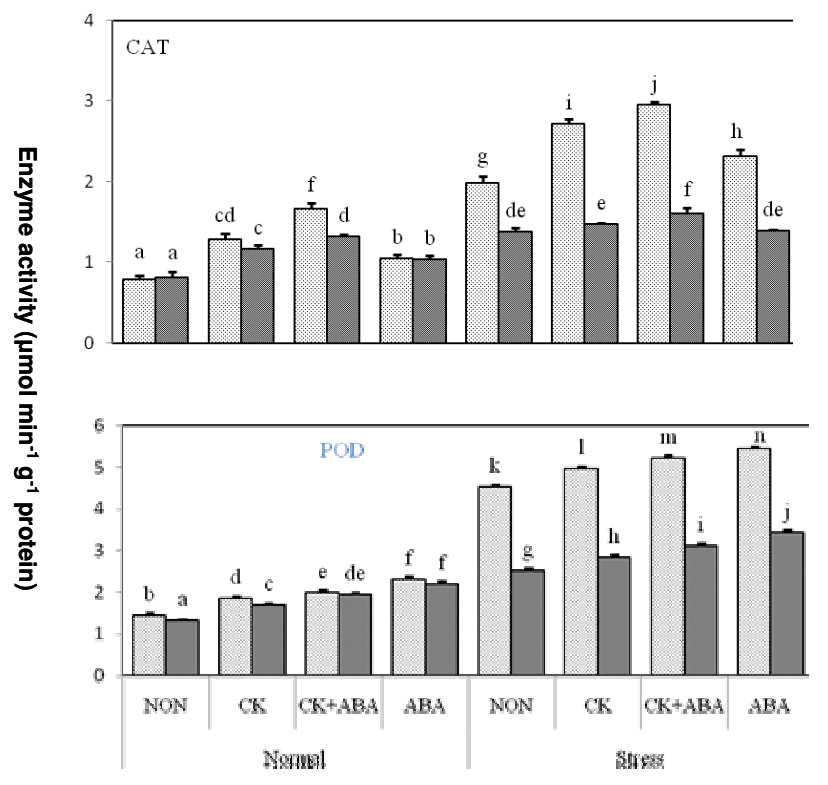

Fig. 5. Effect of hormonal treatments of $\mathrm{CK}, \mathrm{ABA}$ and CK/ABA on enzyme activity of $\alpha$-tocopherol content CAT and POX under irrigation and drought condition in flag leaves during grain filling in two wheat cultivars (drought tolerant cv. 'Pishgam' (white columns) and drought sensitive cv. 'MV-17' (black columns). Data are shown as mean \pm SD of three independent

cultivar can possess a stronger ability to eliminate excessive ROS and reduce lipid peroxidation (Chaves et al., 2003).

The results revealed that under irrigation conditions, CK/ABA caused considerably 110.12 and $62.96 \%$ increase in CAT activity in 'Pishgam' and 'MV-17' at 21 DAA, respectively. Under drought conditions, $\mathrm{CK} / \mathrm{ABA}$ also caused the highest increase in CAT activity of 'Pishgam' and 'MV-17' by 48.24 and $15.94 \%$ at 21 DAA, respectively.

Under both irrigation and drought conditions, $\mathrm{ABA}$ caused significant increase in POD activity of 'Pishgam' by 60.41 and $20.30 \%$ and 'MV-17' by 66.66 and $36.11 \%$ at 21 DAA, respectively (Fig. 5).

A previous study showed that increased amounts of $\mathrm{ABA}$ induced CAT activity during drought conditions in triploid Bermuda grass have been accompanied with $\mathrm{H}_{2} \mathrm{O}_{2}$ and NO production ( $\mathrm{Lu}$ et al., 2009). It has also been shown that the $\mathrm{ABA}$-induced antioxidant enzyme activities in maize leaves require the participation of $\mathrm{H}_{2} \mathrm{O}_{2}$ (Jiang and Zhang, 2003). It seems that ABA-induced $\mathrm{H}_{2} \mathrm{O}_{2}$ accumulation modulated metabolic and redox control pathways in Arabidopsis by influence on many of POD. Moreover, there is an intricate relationship, at the transcriptional and possibly post-transcriptional levels, between $A B A$ biosynthesis and scavenger system of $\mathrm{H}_{2} \mathrm{O}_{2}$ (Ghassemian et al., 2008). Also, this was proved by Synkova et al., (2006) who found that kinetin inhibited a decline in CAT activity. It was concluded that the mechanism of cytokinin-dependent delay in leaf senescence involves the reduction in $\mathrm{H}_{2} \mathrm{O}_{2}$ levels due to the hormone's stimulatory 
effect on CAT and APX activities (Zavaleta-Mancera et al., 2007). Increased activities of ascorbate/glutathione enzymes were detected in cytokinin over-producing tobacco (Nishiyama et al., 2011). Although, in contrary with latter studied works, it was reported that the $\mathrm{CK}$ repress the expression of antioxidant enzymes such as a soybean Fecontaining superoxide dismutase gene (Crowell and Amasino, 1991).

\section{Conclusion}

With regard to different cultivars, the constitutive $\mathrm{H}_{2} \mathrm{O}_{2}$ scavenging enzyme activity and also non-enzymatic antioxidant and osmoprotectant content in the flag leaves of drought-tolerant 'Pishgam' were higher than those in drought-sensitive 'MV-17'. This fact is related to lower $\mathrm{H}_{2} \mathrm{O}_{2}$ content and lipid peroxidation in 'Pishgam' as compared to 'MV-17'. This study reveals that, as compared to drought-sensitive 'MV-17', drought-tolerant 'Pishgam' could successfully activate defensive system and diminish subsequent damage, under drought. Also, tolerant cultivar could use the hormonal treatment better than susceptible cultivar to improve its defensive system. CK/ABA interaction caused the most effect on assayed parameters in many treatments.

\section{Acknowledgements}

The authors thank Dr Ameneh Javid (University of Tehran, International institute of Biochemistry and Biophysics) for critical reading of the manuscript. The authors are grateful to School of pharmacy of Yazd university and International Institute of Biochemistry and Biophysics of Tehran university for sincere collaboration because HPLC analysis of some parameters in this work.

\section{References}

Aebi H (1984). Catalase in vitro. Methods in Enzymology 105:121-126.

Albertson P, Grof CPL (2007). Application of high performance anion exchange-pulsed amperometric detection to measure the activity of key sucrose metabolising enzymes in sugarcane. Journal of Chromatography B-Analytical Technologies in the Biomedical and Life Sciences 845:151-156.

Ashraf M, Foolad MR (2007). Roles of glycine betaine and proline in improving plant abiotic stress resistance. Environmental and Experimental Botany 59:206-216.

Bates LS, Waldren RP, Teare ID (1973). Rapid determination of free proline for water stress studies. Plant and Soil 29:205-207.

Botsoglou ND, Fletouris IP, Mantis A (1998). Rapid gas chromatographic method for simultaneous determination of cholesterol and tocopherol in eggs. Journal of Association of Official Analytical Chemists International 8: 1177-1183.

Chance B, Maehly A (1955). Assay of catalase and peroxidase.
Methods Enzymology 2:764-817.

Chaves MM, Maroco JP, Pereira JS (2003). Underestanding plant responses to drought from genes to the whole plant. Functional Plant Biology 30:239-264.

Chugh V, Kaur N, Gupta AK (2011). Evaluation of oxidative stress tolerance in maize (Zea mays L.) seedlings in response to drought. Indian Journal of Biochemistry and Biophysics 48:47-53.

Crowell DN, Amasino RM (1991). Induction of specific mRNAs in cultured soybean cells during cytokinin or auxin starvation. Plant Physiology 95:711-715.

Dubois M, Gilles KA, Hamilton JK, Rebers PA, Smith F (1956). Colorimetric method for determination of sugars and related substances. Analytical Chemistry 38:350-356.

El-Shahaby OA, Nmatalla MM, Younis ME, El-Bastawisy ZM (2003). Effect of kinetin on photosynthetic activity and carbohydrate content in waterlogged or seawater-treated Vigna sinensis and Zea mays plants. Plant Biosystems 136(2):277-288.

Feyziasl VV, Kasraei R, Moghadam M, Valizadeh G (2004). Studying the detection of the shortage and limitations of food elements absorption by using different methods with consumption of phosphor and zinc in rain-watered Sardari wheat. Agronomical Scientific National Resource Gorgan University (3)11:23-33.

Feyziasl VV, Valizadeh G (2003). The effect of azote consumption and time on rain-watered wheat function. Water Soil Journal (1)17:29-38.

Feyziasl VV, Valizadeh G (2001). Measuring the nitrogen and phosphor need of Sabaln type in complementary irrigation and rain-watered conditions. Journal of Iran Agronomical Science pp. 23-28.

Ghassemian M, Lutes J, Hur-Song C, Lange I, Chen W, Zhu $\mathrm{T}$, Wang $\mathrm{X}$, Lange $\mathrm{M}$ (2008). Abscisic acid-induced modulation of metabolic and redox control pathways in Arabidopsis thaliana. Phytochemistry 69:2899-2911.

Gibson SI (2005). Control of plant development and gene expression by sugar signaling. Current Opinion of Plant Biology 8:93-102.

Gill SS, Tuteja N (2010). Reactive oxygen species and antioxidant machinery in abiotic stress tolerance in crop plants. Plant Physiology and Biochemistry 48:909-930.

Gill PK, Sharma AD, Singh P, Bhullar SS (2003). Changes in germination, growth and soluble sugar contents of Sorghum bicolor (L.) Moench seeds under various abiotic stresses. Plant Growth Regulation 40:157-62.

Goltsev V, Genkov T, Lexa M, Ivanova I (2001). Effect of benzyladenine, 4-PU-30 and thidiazuron on millisecond delayed and prompt chlorophyll fluorescence of Dianthus caryophyllus L. axillary buds cultured in vitro. Scientia Horticulture 891:41-54.

Grieve C, Maas EV (1984). Betaine accumulation in salt stressed sorghum. Physiology of Plant 16:167-171.

Hare PD, Cress WA, Van Staden J (1997). The molecular 
362

basis of cytokinin action. Plant Growth Regulation 23:4178

Heath RL, Packer L (1968). Photoperoxidation in isolated chloroplast I. Kinetics and stoichiometry of fatty acid peroxidation. Archives of Biochemistry and Biophysics 125:189-198.

Jiang M, Zhang J (2003). Cross-talk between calcium and reactive oxygen species originated from NADPH oxidase in abscisic acid-induced antioxidant defence in leaves of maize seedlings. Plant Cell and Environmental 26:929939.

Lantican MA, Dubin HJ, Morris MLS (2005). Impacts of International Wheat Breeding Research in the Developing World 1988-2002. CIMMYT, Mexico

Lee B, Jin Y, Jung W, Avice J, Morvan-Bertrand A (2008). Water-deficit accumulates sugars by starch degradation not by denovo synthesis- in white clover leaves (Trifolium repens). Physiology Plant 134: 403-411.

Liu X, Hua X, Guo J, Qi D, Wang L, Liu Z, Jin Z, Chen S, Liu $G$ (2008). Enhanced tolerance to drought stress in transgenic tobacco plants overexpressing VTE1 for increased tocopherol production from Arabidopsis thaliana. Biotechnology Letters 30:1275-1280.

Liu C, Liu Y, Guo K, Fan D, Li G, Zheng Y, Yu L, Yang R (2011). Effect of drought on pigments, osmotic adjustment and antioxidant enzymes in six woody plant species in karst habitats of southwestern China. Environmental and Experimental Botany 71:174-183.

Mazher A AM, Zaghloul SM, Mahmoud SA, Siam HS (2011). Stimulatory effect of kinetin, ascorbic acid and glutamic acid on growth and chemical constituents of Codiaeum variegatum L. plants. American-Eurasian Journal of Agriculture and Environment Science 10(3):318-323.

Nelson N (1944). A photometric adaptation of the Somogyi method for the determination of glucose. Journal of Biological Chemistry 153:315-80.

Nishiyama R, Watanabe Y, Fujita Y, Le DT, Kojima M, Werner T, Vankova R, Yamaguchi-Shinozaki K, Shinozaki K, Kakimoto T, Sakakibara H, Schmulling T, Tran L-SP (2011). Analysis of cytokinin mutants and regulation of cytokinin metabolic genes reveals important regulatory roles of cytokinins in drought, salt and abscisic acid responses, and abscisic acid biosynthesis. The Plant Cell 23:2169-2183.

Pospisilova J (2003). Participation of Phytohormones in the stomatal regulation of gas exchange during water stress. Biologia Plantarum 46(4):491-506.
Pospisilova J, Synkova H, Rulcova J (2000). Cytokinins and water stress. Biologia Plantarum 43(3):321-328.

Ramiro DA, Guerreiro-Filho O, Mazzafera P (2006). Phenol Contents, oxidase activities, and the resistance of coffee to the leaf miner Leucoptera coffeella. J Chem Ecol 32:19771988.

Seki M, Umezawa T, Urano K, Shinozaki K (2007). Regulatory metabolic networks in drought stress responses. Current Opinion in Plant Biology 10:296-302.

Strizhov N (1997). Differential expression of two P5CS genes controlling proline accumulation during salt stress requires $\mathrm{ABA}$ and is regulated by $A B A 1, A B I 1$ and $A X R 2$ in Arabidopsis. Plant Journal 12:557-569.

Stoparic G, Maksimovic I (2008). The effect of cytokinins on the concentration of hydroxyl radicals and the intensity of lipid peroxidationinn itrogen deficient wheat. Cereal Research Communications 36(4):601-609.

Synkova H, Semoradova S, Schnablova R, Witters E, Husak M, Valcke R (2006). Cytokinin-induced activity of antioxidant enzymes in transgenic Pssu-ipt tobacco during plant ontogeny. Biologia Plantarum 50:31-41.

Velikova V, Yordanov I, Edreva A (2000). Oxidative stress and some antioxidantsystem in acid treated bean plants: protective role of exogenous polyamines. Plant Science 151:59-66.

Verslues PE, Bray EA (2006). Role of abscisic acid (ABA) and Arabidopsis thaliana ABA-insensitive loci in low water potential-induced $\mathrm{ABA}$ and proline accumulation. J Exp Bot 57:201-212.

Wang Z, Quebedeaux B, Stutte GW (1996). Partitioning of (14C) glucose into sorbitol and other carbohydrates in apple under water stress. Australian Journal of Plant Physiology 23:245-251.

Xue G-P, McIntyre CL, Glassop D, Shorter R (2008). Use of expression analysis to dissect alterations in carbohydrate metabolism in wheat leaves during drought stress. Plant Molecular Biology 67:197-214.

Yordanov I, Velikova V, Tsonev T (2000) Plant responses to drought, acclimation and stress tolerance. Photosynthetica Journal 38(2):171-186.

Zavaleta-Mancera HA, Lopez-Delgado $\mathrm{H}$, Loza-Tavera $\mathrm{H}$, Mora-Herrera M, Trevilla-Garcia C, Vargas-Suares M, Ougham H (2007). Cytokinin promotes catalase and ascorbate peroxidase activities and preserves the chloroplast integrity during dark-senescence. Journal of Plant Physiology 164:1572-1582. 